\title{
OS NÍVEIS DE CONHECIMENTOS GEOMÉTRICOS DOS ALUNOS DE UMA ESCOLA PARCEIRA DO PIBID NA PERSPECTIVA DA TEORIA DE VAN HIELE
}

\author{
Francisco Erilson Freire de Oliveira, Luciana de Oliveira Souza Mendonça \\ Instituto Federal de Educação, Ciência e Tecnologia do Ceará, campus de Canindé \\ <erilson_fr@yahoo.com.br><professoralucianamendonca@gmail.com>
}

DOI: 10.21439/conexoes.v9i4.974

\begin{abstract}
Resumo. Esse trabalho objetiva identificar os níveis de conhecimento geométrico dos alunos ingressantes no Ensino Médio de uma escola pública profissionalizante da cidade de Canindé-CE, parceira do PIBID, através do Teste de Van Hiele (TVH) e, consequentemente, realizar um diagnóstico comparativo do desempenho no teste entre as turmas analisadas. Caracterizando-se como uma pesquisa qualitativa e quantitativa. A análise dos resultados foi realizada tomando-se como referencial a Teoria do Desenvolvimento do Pensamento Geométrico do Casal Van Hiele, os Parâmetros Curriculares Nacionais (PCN) e os Descritores de Geometria do Sistema Nacional de Avaliação da Educação Básica (SAEB) para o $9^{\circ}$ Ano do Ensino Fundamental, bem como autores que tratam sobre o ensino e aprendizagem de Geometria. A partir da análise estatística aplicada, percebemos que não foram observadas diferenças estatisticamente significantes entre os resultados obtidos pelas diferentes turmas avaliadas a partir do teste de KruskalWallis. O resultado da pesquisa revelou que $66 \%$ dos alunos pesquisados se enquadraram em um nível menor ou igual a 1, dentre os 5 possíveis. Tais resultados podem decorrer da priorização dada a Álgebra em detrimento da Geometria como afirmam Pavanello (1989) e Meneses (2007). Dessa forma, concluímos que os alunos participantes da pesquisa encontram-se num nível de conhecimento geométrico muito aquém do esperado, indicando que as competências e habilidades de Geometria não foram bem desenvolvidas no processo de ensino aprendizagem de Matemática.
\end{abstract}

Palavras-chaves: Geometria. Teoria de Van Hiele. Estatística.

\begin{abstract}
This study aims to identify the levels of Geometric knowledge of the High School freshmen students of a public school of the Canindé-CE city through the Teste de Van Hiele (TVH) and, therefore, to do a comparative diagnosis of the test performance of the analyzed classes. The study is characterized as a qualitative and quantitative research, at the same time. The analysis of the results was realized having as references the Van Hiele's Geometrical Thought Development Theory, the Parâmetros Curriculares Nacionais (PCN) and the Descritores de Geometria do Sistema Nacional de Avaliação da Educação Básica (SAEB) for the 9th Year of Elementary School, as well as authors who wrote about the teaching and learning of Geometry. As for applied statistics analysis, it was noticed that there were not observed statistically significant differences among the results obtained by the different classes evaluated with the Teste de Kruskal-Wallis. The research results revealed that $66 \%$ of the analyzed students are in a level lower or equal to 1 , out of the 5 possible. Such results may be a consequence of the prioritization given to Algebra to the detriment of Geometry as Pavanello (1989) and Meneses (2007), among others, affirm. We conclude that the students have a level of geometrical knowledge well below what is expected, indicating that the Geometry abilities and competences have not been well developed during the process of teaching-learning Mathematics.
\end{abstract}

Keywords: Geometry. Van Hiele Theory. Statistics. 


\section{INTRODUÇÃO}

Durante muito tempo o ensino de Matemática se caracterizou pelo predomínio de aulas expositivas sendo abordadas de forma abstrata, dificultando o entendimento dos alunos e consequentemente desmotivando-os na construção ativa do conhecimento matemático. Essa característica que foi concebida na época da Matemática Moderna, ainda predomina nas escolas, perpetuada por práticas pedagógicas tradicionais, nas quais os professores de Matemática foram formados e têm impactos e implicações pedagógicas no processo de ensino e aprendizagem de Matemática ainda nos dias atuais.

A problemática do ensino de Matemática fica um pouco mais complicada quando tratamos do ensino de Geometria; pois este conteúdo, segundo Pavanello (1989), na maioria dos casos não é trabalhado em tempo hábil, agravado pelo fato que durante muitos anos, em muitos livros didáticos, ainda se persistia a prática de uma sequência de conteúdos que prioriza a Álgebra em seu detrimento, deixando na maioria das vezes a Geometria em último plano. Temos que levar também em consideração que o excesso de conteúdo a ser ministrado em um ano letivo dificulta que o professor cumpra todo o programa e muitas vezes nem sequer consiga abordar o conteúdo de Geometria, devido a vários problemas de estruturação curricular.

Podemos perceber que esse problema é mais complexo do que parece, tendo uma série de fatores que influenciaram uma organização curricular que não prioriza o ensino de Geometria e que impactam até hoje no ensino dessa área do conhecimento. Dentre as pesquisas sobre essa temática, destaca-se o trabalho de $\mathrm{Pa}$ vanello (1989) que em uma pesquisa histórica sobre as possíveis causas do abandono da Geometria no Brasil, destaca que a priorização da Álgebra em detrimento da Geometria foi fortemente difundida nas escolas e nos livros didáticos pelo Movimento da Matemática Moderna no Brasil a partir da década de 60. Esse movimento buscava tornar a matemática escolar mais próxima da matemática estudada na universidade, portanto enfatizava o rigor lógico e as demonstrações no ensino dessa Ciência.

As pesquisas de Pavanello (1989) e Perez (1991) constatam que independentemente de todo potencial da Geometria, o abandono do seu ensino no Ensino Fundamental e Médio gerou uma fragilidade e ineficiência do ensino de Matemática na Educação Básica que ainda persiste nos dias atuais.

Meneses (2007) nos mostra uma pequena ideia de quando esse esquecimento da Geometria se iniciara quando diz: "Esse abandono percebido principalmente durante os anos de 1960 a 1990, também se refletia nos cursos de graduação de professores e nos cursos de magistério" (MENESES, 2007, p. 4). Dessa forma, percebemos que ouve, de fato, uma grande lacuna em se tratar do ensino dessa área de tão grande importância para o conhecimento humano e que esse fato também teve impactos na formação do professor que em seu processo de escolarização, provavelmente não teve uma boa qualidade de ensino dessa área da Matemática.

Por outro lado, os Parâmetros Curriculares Nacionais (PCN) reafirmam a importância do ensino dos conhecimentos de Geometria, contidos no bloco de conteúdos espaço e forma, para o pleno desenvolvimento do raciocínio lógico-matemático e ampliação das habilidades de pensamento pretendidas para o educando com o estudo da Matemática.

De acordo com os PCN (BRASIL, 1997) a obtenção do pensamento geométrico deve acontecer por todo o Ensino Fundamental (EF) e Ensino Médio (EM), como também, a Geometria não deve ser trabalhada separadamente, ou seja, não deve ser considerada como um conteúdo independente. A Geometria se constitui como um elemento que ajuda a estruturar o pensamento matemático e o raciocínio lógico e dedutivo, permitindo ao estudante estabelecer relações e compreender o espaço que o cerca. Concordando com os PCN (BRASIL, 1997) e Gazire (1988), a Geometria se constitui como um campo fértil para se trabalhar com situações problemas, despertando naturalmente o interesse dos alunos e conduzindo-os a uma aprendizagem reflexiva e significativa.

Toda a importância dada à Geometria infelizmente não se reflete em sala de aula, pois a Álgebra é indiscutivelmente priorizada. As aulas de Geometria são desenvolvidas de maneira desvinculada das outras áreas, além de ser, via de regra, o último conteúdo a ser desenvolvido, correndo até o risco de não ser abordado, por falta de tempo. Segundo Pavanello:

\footnotetext{
Esse costume de programar a geometria para o final do ano letivo é, de certo modo, reforçado pelos livros didáticos que, pelo que pude observar, abordam esse tema quase sempre por último, dando a impressão de que esta é a programação mais conveniente. (PAVANELLO, 1989. p. 6).
}

Com isso, constatamos que "neste cenário em que se coloca o ensino de Geometria, o que se observa é um aprendizado falho, fragmentado, pontual e descontextualizado" (OLIVEIRA, 2012, p. 33) ao contrário do que preconizam os PCN (BRASIL, 1997) que defendem que a ação docente deve, de fato, trazer conhecimentos com significados para a vida do educando e relacionando-os com as demais áreas do conhecimento. 
Devido a grandes dificuldades de nossos alunos atualmente, o EF não tem atendido aos pressupostos e objetivos traçados para o ensino desse conteúdo, o que justifica em paralelo a falta de conhecimento dos conceitos geométricos elementares que se apresentam nos alunos do EM.

Com base nesses aspectos e a necessidade de melhorias no tocante ao ensino e aprendizagem de Geometria, é que nos vimos motivados a diagnosticar e debater sobre quais níveis de conhecimento geométrico se encontram os alunos oriundos da rede municipal de ensino que atualmente se encontram no $1^{\circ}$ Ano do EM, e devido a esta decisão nos ocorreu a seguinte questão problema: Quais os níveis de conhecimentos geométricos dos alunos do $1^{\circ}$ Ano do Ensino Médio, tomando como base os níveis de conhecimento geométricos propostos pelo casal Van Hiele?

A partir desse questionamento, surgiu à proposta de uma pesquisa qualitativa e quantitativa durante o Trabalho de Conclusão de Curso (TCC) de autoria e orientação, respectivamente, de Oliveira (2015) e Mendonça a ser realizada com alunos do $1^{\circ}$ ano do EM através da aplicação do teste de Van Hiele, buscando elucidar quais conhecimentos geométricos os participantes da pesquisa trazem em sua bagagem escolar.

Nesse sentido, esse trabalho que é um recorte do TCC acima citado, tem como objetivo identificar os níveis de conhecimentos geométricos dos alunos ingressantes no EM de uma escola pública profissionalizante da cidade de Canindé - CE através do Teste de Van Hiele e, consequentemente, realizar um diagnóstico comparativo do desempenho no teste entre as três turmas analisadas.

Para tanto, aplicamos um teste diagnóstico (teste de Van Hiele) aos alunos do $1^{\circ}$ Ano do EM de uma escola parceira do Programa Institucional de Bolsas de Iniciação à Docência (PIBID), programa do qual fazemos parte. Posteriormente, analisamos estatisticamente os resultados obtidos pelos alunos e dialogamos com a Teoria do Desenvolvimento do Pensamento Geométrico do Casal Van Hiele, com os PCN e os descritores de Geometria do Sistema Nacional de Avaliação da Educação Básica (SAEB) para o $9^{\circ}$ Ano do Ensino Fundamental, bem como também com alguns autores que tratam sobre o ensino e aprendizagem de Geometria, tais como: Gazire (1988), Lorenzato (1995), Oliveira (2012) e Pavanello (1989).

\section{O MODELO VAN HIELE}

O modelo Van Hiele é o resultado de um estudo realizado pelo casal Dina van Hiele-Geldof e Pierre Marie van Hiele na década de 1950. Trata-se de uma pes- quisa que culminou na tese de doutorado de ambos. $\mathrm{O}$ casal trabalhou com o desenvolvimento do raciocínio no estudo de Geometria Plana, hierarquizando o processo de construção dos conceitos envolvidos na Geometria e identificando os comportamentos do estudante, na aprendizagem, como níveis de maturidade geométrica, onde cada nível sucede o anterior. Desta forma, os pesquisadores estruturaram respectivamente cinco níveis de maturidade geométrica ou níveis de desenvolvimento do pensamento geométrico: Visualização (ou reconhecimento); Análise; Abstração; Dedução; e Rigor (CROWLEY, 1987).

No nível da visualização ou reconhecimento, a compreensão dos educandos sobre as figuras se dá apenas pela visualização e não pelas propriedades, prevalecendo no reconhecimento apenas as formas. Um exemplo disso é a associação de figuras ou sólidos geométricos com objetos semelhantes, conhecidos, como uma caixa de sapato, uma porta, uma bola etc.

O nível da análise caracteriza-se pela percepção do reconhecimento e consequência de algumas propriedades, como também pela utilização destas na resolução de problemas. Neste nível há ênfase nos conceitos envolvidos, pela análise das figuras por seus componentes, como por exemplo, quadrado: 4 lados iguais, 4 ângulos retos, lados opostos iguais e paralelos.

Em relação ao nível da abstração, há a compreensão da importância de uma definição precisa, pelo estudante, mas não do papel dos axiomas. Ocorre a formulação de argumentos informais, acompanhamento e memorização de demonstrações, porém dificilmente os educandos conseguem elaborá-las formalmente, como por exemplo, dizer que todo quadrado é retângulo, mas nem todo retângulo é quadrado. Ou seja, há ausência de formalização.

No nível da dedução, o educando compreende, assim como domina, o processo dedutivo e as demonstrações, diferenciando axiomas, postulados e teoremas, fazendo uso de linguagem matemática precisa. Neste estágio ele consegue, por exemplo, demonstrar propriedades de triângulos e quadriláteros por congruência de triângulos.

O nível do rigor tem como características: a capacidade de compreender demonstrações formais, aptidão para estudo de sistemas axiomáticos distintos (Geometria não euclidiana), capacidade de comparar diferentes sistemas axiomáticos. Os níveis da dedução e do rigor não foram tão explorados pelo casal, visto que não aparecem com frequência em estudantes da educação básica que foram o foco de suas pesquisas. A forma de enquadramento dos alunos nos respectivos níveis de conhecimento geométrico aos quais eles pertencem se dá 

TEORIA DE VAN HIELE

pela resolução de um teste, Teste de Van Hiele (TVH).

Segundo a teoria de Van Hiele, o TVH foi desenvolvido para determinar o nível de desenvolvimento do pensamento em Geometria dos sujeitos da pesquisa, quando essa determinação for possível. O teste foi montado com 25 questões, com 5 delas correspondendo a cada nível e tem como intuito, inferir sobre a comprovação de que cada aluno esteja mesmo no nível ao qual seu comportamento se enquadra. O teste ficou estruturado de forma que as questões de 1 a 5,6 a 10, 11 a 15, 16 a 20 e 21 a 25 corresponderiam aos níveis $1,2,3,4$, e 5 , respectivamente.

O teste foi produzido pelo grupo Cognitive Development and Achievement in Secondary School Geometry CDASSG (USISKIN 1982), este grupo trabalhou com dois critérios diferentes para enquadrar o aluno nos níveis: a) 3 acertos em 5 e b) 4 acertos em 5 . A cada aluno atribuiu-se uma nota que corresponde a uma soma ponderada obtida da seguinte maneira para o critério a:

a.1) 1 ponto por acertar pelo menos 3 dos itens de 1 a 5 (nível 1);

a.2) 2 pontos por acertar pelo menos 3 dos itens de 6 a 10 (nível 2);

a.3) 4 pontos por acertar pelo menos 3 dos itens de 11 a 15 (nível3);

a.4) 8 pontos por acertar pelo menos 3 dos itens de 16 a 20 (nível 4);

a.5) 16 pontos por acertar pelo menos 3 dos itens de 21 a 25 (nível 5).

Para o critério b, a análise é análoga, modificando apenas o número de acertos que é de pelo menos 3 para pelo menos 4 em cada nível como descrito acima. Os pesos atribuídos por nível (do 1 ao 5) correspondem a potências de 2 e ressaltam a ideia do grau de dificuldade das questões crescerem de forma exponencial a medida em que transitamos pelos 5 níveis. Um aspecto que deve ser levado em consideração é a possível ocorrência de erros, tais como: a) o não enquadramento de um aluno que consiga operar com eficiência de praticamente $100 \%$ em um determinado nível; como também, b) o enquadramento indevido de alunos que acertaram 3 ou mais questões de um determinado nível por acaso (chute).

Ao ser adotado o critério de 3 acertos em 5 a probabilidade de ocorrência de erro do tipo b) aumentam, apesar dessa probabilidade apresentar apenas um valor aproximado a $6 \%$ de chances de acertos por acaso. Esse percentual, consideravelmente baixo, tranquiliza o pesquisador ao escolher esse critério para análise, reafirmando a ideia de não comprometer a confiabilidade do trabalho. Com base nisso, utilizaremos tal critério para análise, pois nos permitirá enquadrar um número maior de alunos nos níveis mais elevados.

Dessa forma, ao verificar em quais subgrupos o aluno acertou pelo menos três questões, são atribuídos os pontos, conforme já descrito, e adicionados os mesmos, de forma a obter a soma ponderada por aluno. Esse valor permitirá ou não o enquadramento dos sujeitos como podemos ver na Tabela 1, abaixo:

Tabela 1: Correspondência entre os Níveis de Van Hiele e a Soma Ponderada

\begin{tabular}{|c|c|c|}
\hline Níveis & Pontos atribuídos & Soma ponderada \\
\hline$<1$ & 0 & 0 \\
1 & 1 & 1 \\
2 & 2 & 3 \\
3 & 4 & 7 \\
4 & 8 & 15 \\
15 & 16 & 31 \\
\hline
\end{tabular}

Fonte: Dados da pesquisa.

Usiskin (1982) afirma que este método facilita o processo de enquadramento dos sujeitos, pois permite determinar em quais níveis o critério estabelecido foi alcançado, apenas utilizando a soma ponderada. Assim, um número de 0 a 31 é suficiente para o enquadramento dentre os 5 níveis. Uma soma 3, por exemplo, indica que o aluno atingiu o critério estabelecido para os níveis 1 e 2; uma soma 5 indica que o aluno atingiu o critério estabelecido para os níveis 1 e 3 ; etc.

Porém, uma das características do Modelo van Hiele de desenvolvimento do pensamento geométrico é o fato dele ser sequencial. Para que um aluno seja enquadrado em um nível qualquer é preciso que ele satisfaça o critério estabelecido não apenas para aquele nível, mas também para todos os precedentes. Dessa forma, caso o aluno obtenha uma soma 3, como exemplificado anteriormente, ele satisfez o critério para os níveis 1 (1 ponto) e 2 ( 2 pontos), portanto será enquadrado no nível 2. Por outro lado, se a soma obtida foi 5, ele satisfez o critério para os níveis 1 ( 1 ponto) e 3 (4 pontos), o que não o habilita a ser enquadrado em nenhum dos níveis existentes, pois o critério para o nível 2 não foi alcançado.

Notemos que isso equivale a dizer que somas ponderadas obtidas pelos alunos das quais diferem das mostradas na Tabela 1 referem-se à alunos que não podem ser enquadrados em nenhum nível, dos quais poderão ser classificados com a terminologia "nível indefinido", de acordo com a nomenclatura proposta por 
(OLIVEIRA, 2012).

Outra ocorrência totalmente fora do esperado é a dos sujeitos que não satisfizeram o critério em nenhum dos níveis, nem mesmo no nível 1. Para esses casos, Oliveira (2012), considera por motivos pedagógicos a categoria " $<1$ " (inferior ao nível 1) para tais alunos. Seguido dos cinco níveis de conhecimento, os Van Hiele expressaram cinco características peculiares do modelo e uma sequência didática elencando cinco fases de aprendizagem (CROWLEY, 1987). As características são distribuídas da seguinte forma:

1. Sequencial: O aluno deve passar por todos os níveis, sendo que, não é possível passar de nível sem que domine o nível imediatamente anterior, e consequentemente, todos os outros níveis antecessores.

2. Avanço: A passagem de um nível para outro depende principalmente dos métodos de ensino e do conteúdo, sendo que, a idade ou grau de maturação do aluno não influenciam tão fortemente. Apesar disso, em hipótese alguma nenhum método de ensino permite ao aluno pular por um nível, mesmo que em alguns casos exista uma brevidade em certos níveis, porém em outros casos pode-se acontecer um retardo nesta passagem.

3. Intrínseco e Extrínseco: Os objetivos não tão visíveis em um nível tornam-se bastante explícitos no nível seguinte.

4. Linguística: Cada nível se caracteriza por sua própria linguagem e por um conjunto de relações, interligando-os. Dessa forma, uma relação dita "correta" em certo nível, pode chegar a se modificar em outro nível seguinte.

5. Combinação inadequada: O professor em hipótese alguma poderá raciocinar em um nível diferente do aluno, caso isso aconteça, o aprendizado não ocorre. Ou seja, o conteúdo, o material didático e principalmente o vocabulário do professor devem estar compatíveis com o nível ao qual o aluno se encontra.

Van Hiele destaca que a mudança de um nível para o outro não se dá por meio de processos naturais, e sim pela influência do professor através de um programa de ensino (VAN HIELE, 1986). Tal programa inclui uma sequência didática contendo cinco fases como já mencionado.

Fase 1 - Informação: Professor e aluno conversam de modo a desenvolver atividades sobre os objetos de estudo do nível em questão. Nessa fase, é introduzido o vocabulário específico do nível, são feitas perguntas e observações. Essa fase se torna uma espécie de preparação para estudos futuros.

Fase 2 - Orientação dirigida: Através do uso de materiais preparados pelo professor, são desenvolvidas atividades com intuito de explorar bastante as características de um nível.

Fase 3 - Explicação: Nesta fase, o papel do professor é fundamentalmente de orientar o aluno por meio de uma linguagem apropriada. Com base nas experiências anteriores e nas orientações do professor, os alunos conseguem revelar seus pensamentos e modificar seus pontos de vista sobre as estruturas trabalhadas e observadas podendo assim compreender tais estruturas.

Fase 4 - Orientação livre: Neste momento, através do material disponibilizado pelo professor, os alunos procuram soluções particulares à tarefas mais complexas, e tais soluções podem ser realizadas de maneiras diferentes, gerando assim certa experiência ao descobrir sua própria maneira de solucionar as tarefas.

Fase 5 - Integração: Por fim, o aluno revê e resume tudo que foi aprendido, objetivando formar uma visão mais geral da nova rede de objetos e relações, dessa forma, o aluno consegue alcançar um novo nível de pensamento.

Analisando algumas pesquisas que tratam da temática do ensino de Geometria, acreditamos que o trabalho baseado na teoria de Van Hiele pode ser uma boa alternativa teórico-metodológica para que o ensino desse conteúdo seja ressignificado não só pelos alunos, que poderão aprendê-los de forma significativa, mas também para os docentes ou futuros docentes de Matemática, que poderão ser encorajados, a partir dessa experiência, a desenvolverem diferentes formas de ensinar e a analisarem o processo de ensino e aprendizagem tendo como referencial a Teoria de Van Hiele.

Nesse sentido, acreditamos que essa pesquisa trará contribuições importantes a essa temática, principalmente no que se refere a um diagnóstico preliminar sobre os níveis de conhecimentos geométricos dos alunos participantes da pesquisa, que representam aproximadamente $90,6 \%$ dos alunos ingressantes no ensino médio profissionalizante de uma escola pública de $\mathrm{Ca}$ nindé.

Além disso, gostaríamos de ressaltar também, as contribuições dessa pesquisa para o pesquisador, que está em processo de formação inicial no curso de Licenciatura em Matemática do IFCE Campus Canindé, inserido no Programa Institucional de Bolsas de Iniciação a Docência - PIBID Capes, que teve a oportunidade de pesquisar esta temática, entendendo como se 
dá o processo de ensino e aprendizagem de Geometria, com uma preocupação de aperfeiçoar a sua prática pedagógica nas escolas públicas de Canindé e região.

\section{APRESENTAÇÃO E ANÁLISE DOS DADOS}

O Universo da pesquisa é uma escola estadual da cidade de Canindé, com seis (6) anos de funcionamento, que atende atualmente quatrocentos e dezessete (417) alunos da cidade de Canindé e cidades circunvizinhas e funciona nos turnos manhã e tarde, sendo ambos com as mesmas turmas, pois se enquadra no regime de tempo integral de ensino.

Como população, participaram os alunos do $1^{\circ} \mathrm{Ano}$ do EM das três (3) turmas existentes, das quais nomeamos por Turma A, Turma B e Turma C, que totalizam cento e dezessete (117) alunos, porém nos dias das aplicações, tivemos a presença de cento e seis (106) alunos que representam aproximadamente $90,6 \%$ aptos a participarem da pesquisa, considerando esse número bastante significativo para esse estudo. Tais alunos foram nomeados de Aluno 1, 2, 3, .., 106. Os alunos 1 à 34 fazem parte da Turma A, 35 à 68 da Turma B e os alunos 69 à 106 da Turma C.

\subsection{Análise Descritiva dos Testes de Van Hiele}

Após a aplicação dos testes e de posse das folhas de respostas dos alunos, passamos a avaliação do nível de desenvolvimento do pensamento geométrico, de cada aluno. Baseando-nos na proposta original do projeto CDASSG para a avaliação dos resultados obtidos e o possível enquadramento dos sujeitos nos níveis de Van Hiele nos apoiamos na Estatística. Segundo Guimarães (2008):

Estatística é um conjunto de técnicas de análise de dados, cientificamente formuladas, aplicáveis a quase todas as áreas do conhecimento que nos auxiliam no processo de tomada de decisão. É a Ciência que estuda os processos de coleta, organização, análise e interpretação de dados relevantes e referentes a uma área particular de investigação. (GUIMARÃES, 2008, p. 11).

Com base nisso, inicialmente corrigimos cada prova construindo uma tabela de frequência pelos acertos por questão, por aluno e por turma. A partir dessa tabela obtivemos os dados do Gráfico 1 para análise dos acertos por questão e por nível de conhecimento.

A partir do Gráfico 1, podemos perceber que de fato o teste possui um caráter ascendente de dificuldade, de acordo com a literatura, pois no nível 1 tivemos uma quantidade bem maior de acertos e esses vão decrescendo a medida em que os níveis crescem.

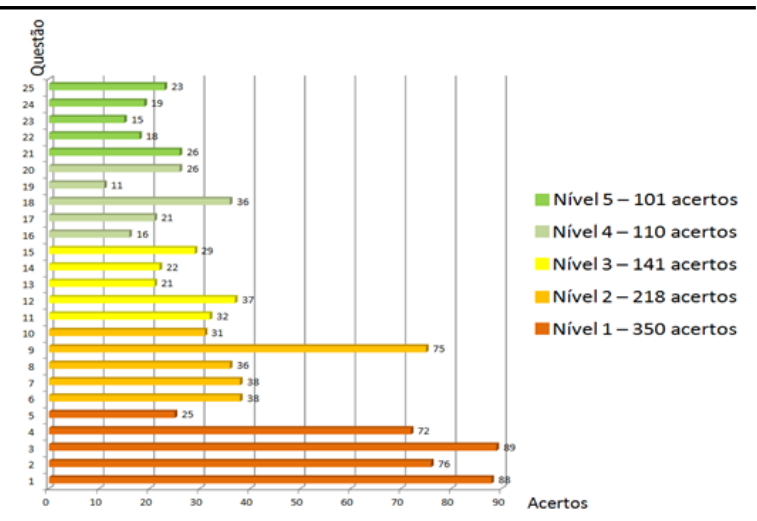

Gráfico 1: Acertos por questão e acertos por nível Fonte: Dados da Pesquisa

Analisando por meio de percentuais, onde todos os possíveis acertos seriam no total 530 por cada nível, haja vista que cada nível possui 5 questões e que participaram 106 alunos. No nível 1 (questões de 1 à 5), somando todas as respostas corretas, obtivemos $66 \%$ de acertos, no nível 2, que inclui as questões de 6 à 10, temos $42 \%$ dos acertos possíveis, caindo para $27 \%$ no nível 3 (questões de 11 à 15), 21\% no Nível 4 que compreende as questões de 16 à 20, e apenas $19 \%$ no nível 5 (questões de 21 à 25).

Além disso, analisamos as questões de forma individual, onde temos um máximo de 106 acertos por questão. No nível da visualização (nível 1) tivemos a questão de número 3 com maior índice de acertos (84\%). Esta questão trata da identificação dos retângulos. Com o menor número de acertos $(23,5 \%)$, temos a questão 5 que, por sua vez, trata da inferência sobre o paralelogramo (Figura 1).

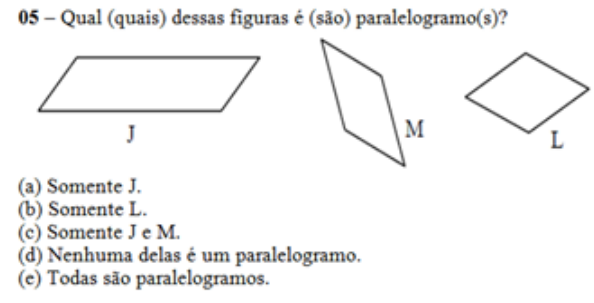

Figura 1: Representação da questão 05 do TVH Fonte: Oliveira (2012)

Para a resolução correta desta, como das outras 4 primeiras questões, é necessário apenas o reconhecimento por meio da visualização como o próprio referencial teórico descreve. Considerando os Descritores 
das Matrizes de Matemática do $9^{\circ}$ ano do EF (BRASIL. 2008) disponibilizado pelo Sistema Nacional de Avaliação da Educação Básica (SAEB), os alunos demonstraram dificuldades em relação aos descritores 2 e 4 que inferem respectivamente sobre a Identificação de propriedades comuns e diferenças entre figuras bidimensionais; e Identificação de relações entre quadriláteros, por meio de suas propriedades.

No nível 2 (Análise), obtivemos a questão 9 com maior índice de acertos $(71 \%)$. Esta solicita ao aluno o conhecimento das propriedades dos triângulos isósceles. Do lado oposto a essa situação tivemos a questão que apresentou o menor número de acertos (30\%), questão 10. Esta solicita ao aluno um conhecimento em relação às propriedades dos círculos relacionando com os raios e os ângulos do quadrilátero formado, tendo os centros e os pontos de interseção entre os círculos como vértices (Figura 2).

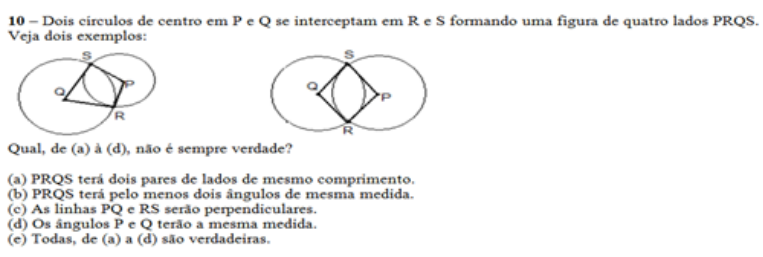

Figura 2: Representação da questão 10 do TVH Fonte: Oliveira (2012)

Ao responder tal questão, o aluno demonstra competências e habilidades relativas ao descritor 4: Identificar relação entre quadriláteros, por meio de suas propriedades; e descritor 11: Reconhecer círculo/circunferência, seus elementos e algumas de suas relações. Porém estas competências ainda não foram bem desenvolvidas pela população pesquisada.

No nível 3, a questão 12 teve maior número de acertos, mesmo com o fato de apenas $35 \%$ dos alunos terem acertado. Tal questão solicita que o aluno infira sobre as propriedades dos triângulos equiláteros, bem como suas implicações. Neste nível, a questão 13 foi a que teve menor índice de acertos (20\%) (Figura 3), no item o aluno é indagado sobre as propriedades dos retângulos, solicitando resposta em que o aluno identifique o quadrado também como um retângulo, a partir da inclusão de classes.

Esta questão também está relacionada aos descritores: 2, que tem como competência a Identificação das propriedades comuns e diferenças entre figuras bidimensionais; 4, Identificação de relação entre quadriláteros, por meio de suas propriedades; e 6, Reconhecer ângulos como mudança de direção ou giros, identificando ângulos retos e não-retos.

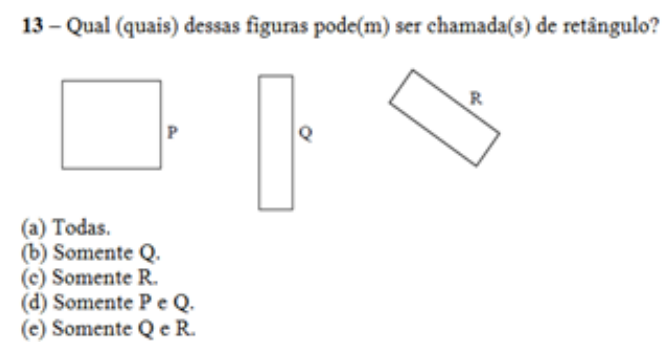

Figura 3: Representação da questão 13 do TVH Fonte: Oliveira (2012)

No Nível 4 (Dedução), tivemos a $18^{\mathrm{a}}$ questão com o número mais elevado de acertos, com apenas $34 \%$ dos possíveis. Para a resolução desta, é necessário que o aluno tenha compreensão de implicações lógicas bem como pelo menos um mínimo de domínio de processos dedutivos. Por outro lado, com o menor número de acertos, inclusive em comparação a todas as questões do teste, temos a questão 19 exposta na Figura 4 abaixo, com apenas 11 dos 106 alunos tendo acertado, configurando-se apenas com aproximadamente 10,5\% dos acertos possíveis. Nesta questão o aluno é indagado sobre a compreensão dos axiomas e definições da Geometria.

19 - Em geometria:

(a) Todo termo pode ser definido e toda afirmação verdadeira pode ser provada.

(b) Todo termo pode ser definido, mas é necessário assumir que certas afirmaçōes são verdadeiras.

(c) Alguns termos têm que ser deixados sem definição, mas toda afirmaçăo verdadeira pode ser provada.

(d) Alguns termos têm que ser deixados sem definiçăo e isto é necessário para quue se tenhamalgumas afirmaçōes que são assumidas como verdadeiras.

(e) Nenhuma, de (a) a (d) está correta.

Figura 4: Representação da questão 19 do TVH Fonte: Oliveira (2012)

Por sua vez, esta competência não é contemplada nos descritores do SAEB, corroborando para com o trabalho dos Van Hiele, que afirma que os níveis quatro e cinco não são alcançados pela maioria dos alunos do EF e que por esse motivo suas pesquisas não aprofundaram os estudos nesses níveis.

Por fim, no nível 5 (Rigor), com apenas 24,5\% dos acertos possíveis, tivemos a questão 21 como a mais acertada. Esta, trata da capacidade de estabelecer e comparar diferentes sistemas matemáticos, ou seja, Geometria não euclidiana. Com o pior resultado deste nível, temos a questão 23 , com $14 \%$. A resolução desta questão requer a mesma capacidade de resolução da anterior. 
23 - Existe uma geometria, inventada por um matemático J, na qual a seguinte afirmação é verdadeira: "A soma as medidas dos ângulos internos de um triângulo é menor do que $180^{\circ}$." Qual das afirmativas abaixo é correta?

(a) J cometeu um erro ao medir os ângulos do triângulo.

(b) J cometeu um erro de raciocinio lógico.

(c) J tem uma idéia errada do que se entende por verdadeiro.

(d) J comecou com pressupostos diferentes daqueles da geometria usual.

(e) Nenhuma, de (a) a (d) está correta.

Figura 5: Representação da questão 23 do TVH Fonte: Oliveira 2012)

Como já mencionado, esta questão não estabelece relação com os descritores do SAEB como também não foi tão explorada pelos Van Hiele, agora devido ao fato de estarmos trabalhando com Geometria não euclidiana. Dessa forma, passamos para a classificação dos alunos por nível de desenvolvimento do pensamento geométrico.

\subsection{Classificação dos Sujeitos por Nível de Desen- volvimento do Pensamento Geométrico}

Apesar da possibilidade de utilização de 4 acertos em 5 para o enquadramento do aluno ser mais rigoroso, seguimos o critério utilizado por Oliveira (2012), de pelo menos 3 acertos das cinco questões distribuídas de cada nível, por conseguirmos um percentual maior de alunos nos níveis mais altos.

Seguindo esta metodologia, assim como a descrita no referencial teórico-metodológico, corrigimos todas as provas dos alunos das três turmas, em que participaram do teste respectivamente 34,34 e 38 alunos, totalizando 106 alunos, e obtivemos resultados a partir da distribuição dos alunos segundo os níveis de Van Hiele como mostra o Gráfico 2 abaixo.

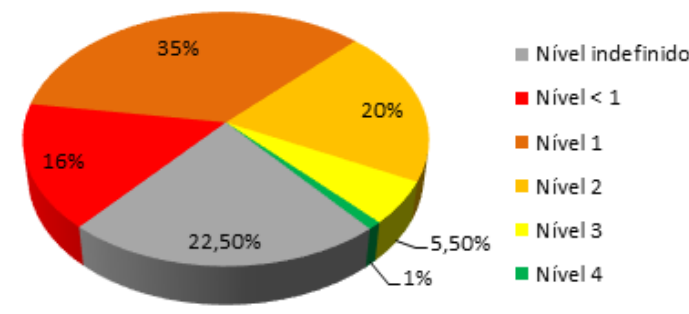

Gráfico 2: Enquadramento de todos os alunos nos níveis de Van Hiele

Fonte: Dados da pesquisa

Observando o Gráfico 2 acima, nota-se que 22,5\% dos participantes da pesquisa não puderam ser enquadrados em nenhum nível, levando-se em consideração às exigências do modelo de Van Hiele para classificação, sendo necessário 3 acertos por nível e, de forma sequencial, para enquadramento de nível proposto. Dessa forma, o setor cinza do gráfico setorial refere-se aos alunos que não puderam ser enquadrados em nenhum nível, aos quais classificamos com a terminologia "nível indefinido", de acordo com a nomenclatura proposta por Oliveira (2012).

Por outro lado, somando-se apenas as porcentagens dos alunos que foram enquadrados em algum nível, os dados do Gráfico 2 indicam que $51 \%$ alunos encontramse em um nível menor ou igual a 1 , não chegando ao nível 2 que seria o nível da análise, caracterizado pela percepção do reconhecimento e consequência de algumas propriedades, como também pela utilização destas na resolução de problemas, e que $16 \%$ dos alunos sequer poderiam ser enquadrados no nível 1 que se refere ao nível da visualização ou reconhecimento. Como já mencionado no referencial, neste nível a compreensão dos educandos sobre as figuras se dá apenas pela visualização e não pelas propriedades, prevalecendo no reconhecimento apenas as formas. Esses dados nos impressionaram de maneira marcante. Tínhamos como hipótese que os resultados não seriam bons, porém, pode ser observado que os alunos apresentaram mais dificuldades do que o esperado.

Para facilitar a comparação entre as 3 turmas (A, B e C) de forma individual, como também para vermos se existe alguma diferença entre elas, construímos o Gráfico 3 que apresenta o enquadramento dos alunos nos níveis de Van Hiele separados por turmas.

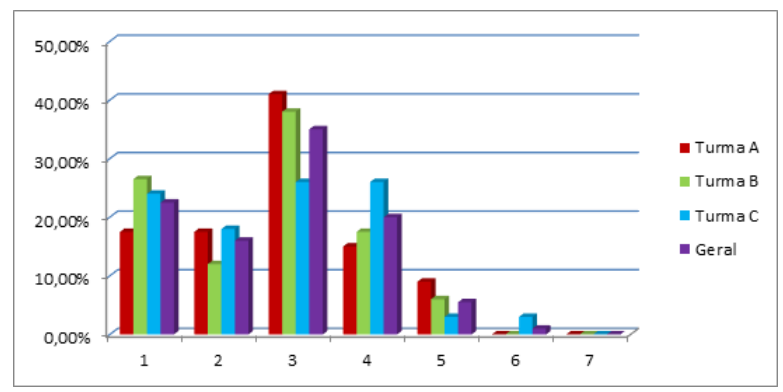

Gráfico 3: Enquadramento dos alunos nos níveis de Van Hiele por turmas

Fonte: Dados da Pesquisa

Fica explícito que nenhum aluno conseguiu mostrar conhecimento geométrico referente ao nível cinco e apenas a Turma C possui aluno no nível 4 , sendo $3 \%$ dela, onde de forma geral se refere a apenas $1 \%$ dos alunos avaliados. A Turma A obteve um maior percentual de alunos no nível três (9\%), e com o menor percentual 
temos a Turma C (3\%). Este nível é caracterizado como completamente possível de se chegar enquanto aluno do EF como descreve o casal Van Hiele, porém este percentual se apresenta muito aquém do que realmente deveríamos obter. No nível 2, os papeis se invertem, a Turma $\mathrm{C}$ encontra-se com o maior percentual de alunos (26\%), ficando a Turma A com 15\% dos alunos neste nível, sendo o menor percentual.

O nível 1 se caracteriza como o nível que mais obtém alunos, sendo $41 \%$ dos alunos da Turma A que é detentora da maior classificação de seus alunos nesse nível, e menor enquadramento dos alunos nesse nível a Turma C, ficando com $26 \%$ deles. O nível $<1$ apresenta um percentual bastante significativo de alunos. Neste nível temos $18 \%$ dos alunos da Turma $\mathrm{C}$ enquadrados, enquanto que apenas $12 \%$ dos alunos da Turma B se mostraram com esse nível de conhecimento.

Chegando por fim nos alunos com nível Indefinido. Com esta característica temos 26,5\% dos alunos da Turma B, sendo a turma com maior índice de alunos que não puderam ser enquadrados nos níveis de Van Hiele, de acordo com a metodologia adotada. Já a Turma A apresentou o menor índice, com apenas $17,5 \%$ de seus alunos. Percebemos que os resultados apresentaram alternância entre turma com maior e menor índice de alunos enquadrados em um nível específico. Devido a essa visão, pensamos que poderiam existir algumas diferenças estatísticas significativas permeando estas turmas.

Para podermos analisar essas possíveis diferenças, aplicamos o teste de Kruskal-Wallis. Tal teste, segundo Doria Filho (1999), é utilizado frequentemente para testes não-paramétricos, e figura no ranking dos mais utilizados. Este teste é utilizado para dados provenientes de três ou mais amostras. Ele é usado para testar a hipótese de que todas as populações possuem distribuições iguais; quando o teste de Kruskal-Wallis conduz a resultados significativos, ou seja, o valor $\mathrm{p}<0,05$, então pelo menos uma das amostras é diferente das restantes (AYRES et al., 2007).

Fizemos o teste descrito utilizando o Software BioEstat 5.3 1 AYRES et al., 2007) desenvolvido pelo Instituto de Desenvolvimento Sustentável Mamirauá. Após a realização da análise estatística, verificou-se que à ausência de diferenças estatisticamente significantes entre as turmas analisadas $(\mathrm{p}=0,6395)$.

Passando por essa fase de testagem das três turmas e, consequentemente, a aferição de que elas se apresentam com distribuições iguais, ou seja, sem diferenças significativas, analisaremos agora apenas os alunos dos quais conseguimos enquadrar em algum nível. Assim,

\footnotetext{
${ }^{1}$ Software disponível em: http://www.mamiraua.org.br/ptbr/downloads/programas/bioestat-versao-53/.
}

obtemos os dados da Tabela 2.

Analisando a Tabela 2, com a apresentação dos alunos que foram enquadrados em algum nível, ou seja, retirando-se da amostra os indefinidos. Ao relacionarmos os dados dos Gráficos 2 e 3 notamos que o índice passou de $51 \%$ para $66 \%$ dos alunos que encontram-se em um nível menor ou igual a 1 , e que $21 \%$ dos alunos sequer poderiam ser enquadrados no nível 1 que se refere ao nível da visualização ou reconhecimento.

Observando a Tabela 2 de acordo com a metodologia descrita, observamos que cerca de $99 \%$ dos alunos foram classificados segundo um nível igual ou inferior ao 3 e $92 \%$ foram classificados segundo um nível igual ou inferior ao 2. O percentual aproximado de alunos que foram classificados segundo o nível 3 foi de apenas $7 \%$, enquanto os que foram classificados no nível 2 foi de $26 \%$. Isso implica, como já foi mencionado, que $66 \%$ dos alunos foram classificados nos níveis iguais ou inferiores ao nível 1 de conhecimento geométrico.

Nossos dados indicam um pior resultado em relação aos dados encontrados na pesquisa de Oliveira (2012), seguindo também a mesma metodologia de análise, sem os indefinidos, que na aplicação do pré-teste, classificou 96\% dos alunos segundo um nível igual ou inferior ao 3; $73 \%$ dos alunos classificados no nível igual ou inferior a 2 e aproximadamente $60 \%$ dos alunos classificados segundo os níveis 2 e 3 .

Tal resultado, mesmo sendo melhor do que os encontramos em nossa pesquisa, ainda se configuram aquém dos conhecimentos geométricos propostos nos PCN bem como nos descritores do SAEB, dos quais indicam habilidades e competências a serem desenvolvidas pelos alunos durante o EF que não estão sendo efetivamente alcançadas por eles durante este nível de escolaridade.

Por outro lado, as discussões das diversas pesquisas que Pusey (2003) faz em seu trabalho, são corroboradas por nosso resultado, pois segundo o autor a maioria dos alunos americanos chegam à universidade raciocinando, segundo os níveis 1 e 2. Em nossa pesquisa constatamos que aproximadamente $55 \%$ da nossa população em análise (ver Gráficos 2 e/ou 3 se encontram nesses níveis. Rezi (2001); Usiskin (1982); e Burger e Shaughnessy (1985) também obtiveram resultados semelhantes aos que encontramos.

\section{CONSIDERAÇÕES FINAIS}

As pesquisas de Pavanello (1989), Perez (1991) e Gazire (2000) constatam que a Álgebra foi indiscutivelmente priorizada em detrimento à Geometria, e que todo o processo de abandono ainda se reflete negativamente nos dias atuais. Somos conhecedores de todo o 

TEORIA DE VAN HIELE

Tabela 2: Classificação dos sujeitos de acordo com os níveis de van Hiele sem os indefinidos

\begin{tabular}{|c|c|c|c|c|c|c|c|c|}
\hline Nível & Turma A & $\%$ & Turma B & $\%$ & Turma C & $\%$ & Geral & $\%$ \\
\hline$<1$ & 6 & 21,5 & 4 & 16 & 7 & 24 & 17 & 21 \\
\hline 1 & 14 & 50 & 13 & 52 & 10 & 34,5 & 37 & 45 \\
2 & 5 & 18 & 6 & 24 & 10 & 34,5 & 21 & 26 \\
3 & 3 & 10,5 & 2 & 8 & 1 & 3,5 & 6 & 7 \\
4 & 0 & 0 & 0 & 0 & 1 & 3,5 & 1 & 1 \\
5 & 0 & 0 & 0 & 0 & 0 & 0 & 0 & 0 \\
Total & 28 & 100 & 25 & 100 & 29 & 100 & 82 & 100 \\
\hline \multicolumn{8}{|c|}{ Fonte: Dados da pesquisa. }
\end{tabular}

potencial intrínseco na Geometria, e que o ensino desta área acarreta benefícios incomensuráveis para a vida do educando, principalmente quando apresentado por meio de relações com o cotidiano dos sujeitos em formação, como também a partir de uma metodologia que utilize recursos didáticos diferenciados, priorizando a aprendizagem ativa dos educandos.

Por isso, consideramos ser necessário um trabalho docente voltado essencialmente para a construção do conhecimento matemático de forma significativa e conectada com a realidade dos alunos, principalmente no tocante a Geometria. Devido a todo esse processo de relegação da Geometria, os índices de aprendizagem desta área continuam abaixo do que realmente almejamos em si tratar da Educação Básica.

Ratificando isso, os níveis de conhecimento geométrico apresentados pelos sujeitos dessa pesquisa, a partir da resolução do teste de Van Hiele, se expressam muito aquém do esperado para a nossa educação básica. Isso devido termos observado que $66 \%$ dos alunos pesquisados se enquadraram em um nível menor ou igual a 1 . $\mathrm{O}$ que nos leva a refletir que as competências e habilidades de Geometria indicadas tanto pelos PCN como pelos descritores do SAEB não foram bem desenvolvidas pelos alunos avaliados. Esta característica encontrada possivelmente decorre da forma como tem sido ensinada essa área da Matemática, como afirmam Lorenzato (1995) e Pavanello (1989).

De maneira geral, os resultados dos testes foram piores que os encontrados por Oliveira (2012). Mas que também diferem de dados socioeconômicos e Educacionais, uma vez que a pesquisa de Oliveira (2012) foi desenvolvida com sujeitos da cidade de Ouro Branco - Minas Gerais que possui IDH de Renda 0,753 e IDH de Educação 0,680 enquanto que Canindé apresenta um IDH de Renda 0,571 e de Educação 0,526, configurando-se como uma cidade de baixo Índice de Desenvolvimento Humano Educacional.
Recomendamos a possibilidade de continuidade desse trabalho a partir da utilização dos dados já coletados para uma intervenção, embasada em Oliveira (2012), para constatar se realmente um trabalho interventivo ajudará para com a amenização dos resultados ora encontrados e consequentemente contribuir para a transposição de dificuldades de aprendizagem em Geometria concernentes a escolarização básica de nossos munícipes.

\section{REFERÊNCIAS}

AYRES, M.; AYRES JÚNIOR, M.; AYRES, D. L.; SANTOS, A. BIOESTAT - Aplicações estatísticas nas áreas das Ciências Bio-Médicas. Belém: Mamirauá, 2007.

BRASIL. Secretaria de Educação Fundamental, Parâmetros Curriculares Nacionais: Matemática. Brasília, 1997.

PDE : Plano de Desenvolvimento da Educação:

Prova Brasil : ensino fundamental : matrizes de referência, tópicos e descritores. Brasília, 2008.

CROWLEY, M. L. The van hiele model of the development of geometric thought. Mary Montgomery Lindquist. Learning and Teaching Geometry, K-12., p. 1-16, 1987.

DORIA FILHO, U. Introdução a Bioestatística: para simples mortais. São Paulo: Negócio Editora, 1999.

GAZIRE, E. S. Perspectivas da resolução de problemas em educação matemática. Dissertação (Dissertação (Mestrado em Educação Matemática)) — Universidade Estadual Paulista "Júlio de Mesquita Filho", Instituto de Geociências e Ciências Exatas, Rio Claro, 1988. 
GAZIRE, E. S. O não resgate das geometrias. Tese

(Tese de Doutorado) - Universidade Estadual de

Campinas, Faculdade de Educação, Campinas, 2000.

GUIMARÃES, P. R. B. Métodos Quantitativos

Estatísticos. Curitiba: IESDE Brasil S.A., 2008.

LORENZATO, S. Por que não ensinar geometria?

Revista da Sociedade Brasileira de Educação

Matemática, n. 4, p. 3-13, 1995.

MENESES, R. S. Uma história da geometria escolar no Brasil: de disciplina a conteúdo de ensino.

Dissertação (Dissertação (Mestrado em Educação)) PUC, São Paulo, 2007.

OLIVEIRA, F. E. F. Os Níveis de Conhecimentos Geométricos dos Alunos Ingressantes No Ensino Médio e a Teoria de Van Hiele. Dissertação (Monografia (Licenciatura em Matemática)) - Instituto Federal de Educação, Ciência e Tecnologia do Ceará, Canindé, 2015.

OLIVEIRA, M. C. Ressignificando conceitos de geometria plana a partir do estudo de sólidos geométricos. Dissertação (Dissertação (Mestrado em Ensino de Ciências e Matemática)) - Pontifícia Universidade Católica de Minas Gerais - PUC Minas, Belo Horizonte, 2012.

PAVANELLO, M. R. O abandono do ensino de Geometria: Uma visão histórica. Dissertação (Dissertação (Mestrado em Educação: Metodologia do Ensino)) — Faculdade de Educação, UNICAMP, Campinas, 1989.

PEREZ, G. Pressupostos e reflexões teóricas e metodológicas da pesquisa participante no ensino de geometria para as camadas populares. Tese (Tese (Doutorado em Educação: Metodologia do Ensino)) - Universidade Estadual de Campinas, Faculdade de Educação, Campinas, 1991.

PUSEY, E. L. The van Hiele model of reasoning in geometry: A literature review. Dissertação (Dissertação (Mestrado em Educação Matemática)) — North Carolina State University, Raleigh, 2003.

USISKIN, Z. Van Hiele levels and achievement in secondary school geometry. Tese (Doutorado) - The University of Chicago, Chicago, 1982. Disponível em: <http://ucsmp.uchicago.edu/resources/van_hiele_ levels.pdf $>$

VAN HIELE, P. M. Structure and Insight: A Theory of Mathematics Education. Orlando: Academic Press, 1986. 